\title{
Probing The Non-Generalized Amyloid Inhibitory Mechanism Of Hydrophobic Chaperone
}

\author{
Aiman Masroor, Nida Zaidi ${ }^{\dagger}$, Tajalli I. Chandel ${ }^{\dagger}$, Zoha Aqueel, Sadia \\ Malik, Rizwan H. Khan*
}

Interdisciplinary Biotechnology Unit, Aligarh Muslim University, Aligarh, 202002, India

$\uparrow$ Authors contributed equally

*To whom correspondence should be addressed. E-mail: rizwanhkhan@hotmail.com; rizwanhkhan1@gmail.com; Fax:+91-571-2721776; Tel.: +91-571-2720388. 
Table S1. The $\alpha$-helical content of HSA alone and HSA pre titrated with PB on ITC.

\begin{tabular}{lcccc}
\hline Sample & Temperature & MRE $22 n m$ & \% $\boldsymbol{\alpha}$ helix & \% $\boldsymbol{\beta}$ sheet \\
\hline HSA & $\left(25^{\circ} \mathrm{C}\right)$ & -18919.0 & 54.6 & 8.7 \\
HSA:PB (1:10) & & -20059.7 & 62.3 & 7.8 \\
HSA & $\left(65^{\circ} \mathrm{C}\right)$ & -16279.0 & 44.0 & 11.3 \\
HSA:PB (1:10) & & -16714.2 & 46.5 & 10.8 \\
\hline
\end{tabular}



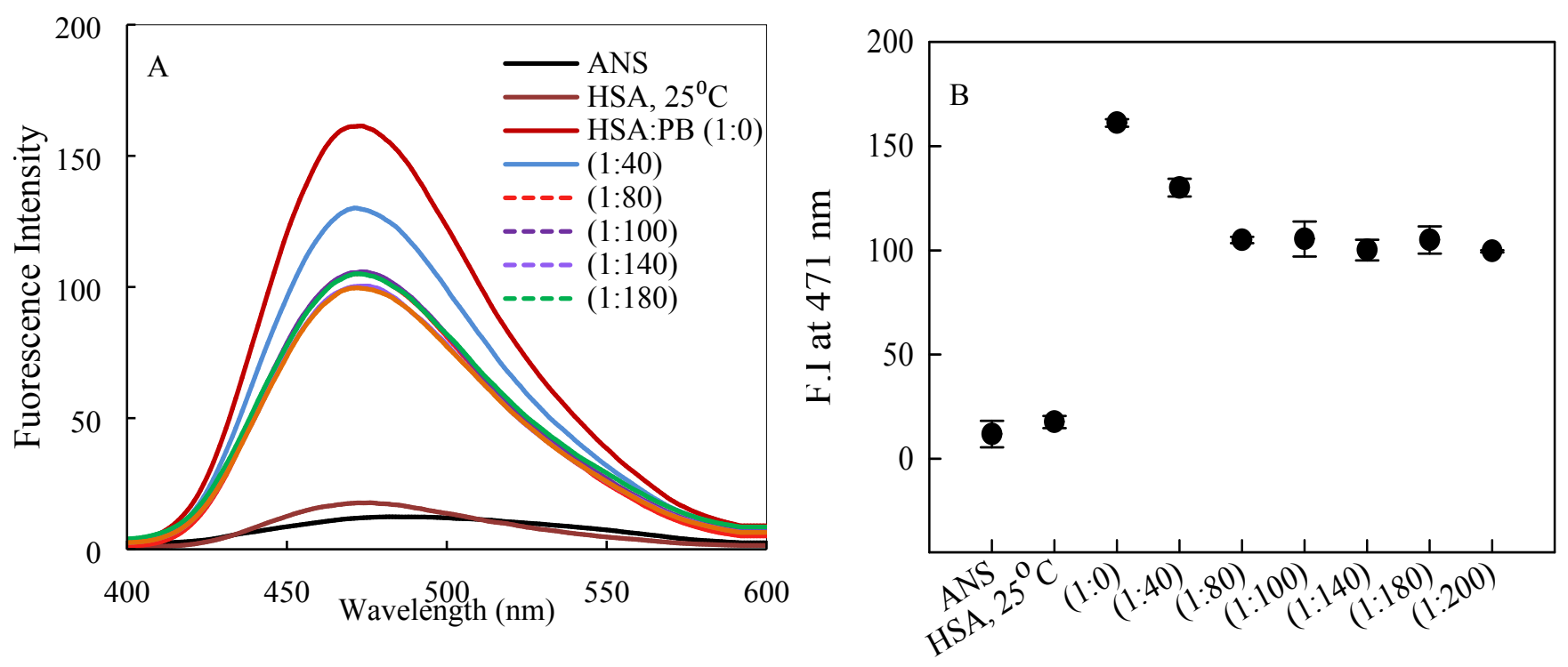

Figure S1. (A) ANS fluorescence spectra of samples with varying molar ratio of HSA to PB incubated at $65^{\circ} \mathrm{C}, \mathrm{pH} 7.4$ for $120 \mathrm{~h}$ and (B) ANS fluorescence intensity at $471 \mathrm{~nm}$ represented in the form of a scattered plot 


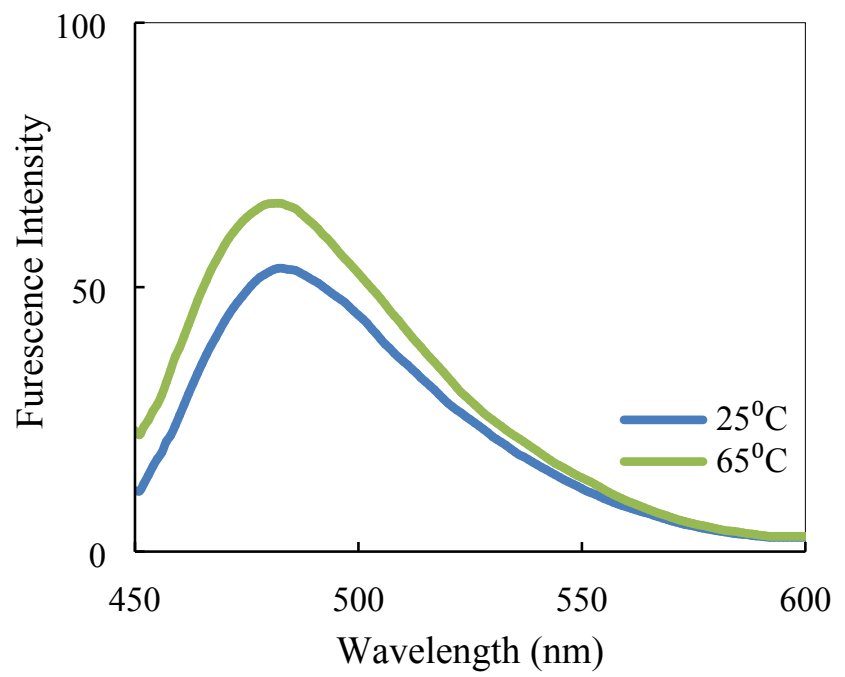

Figure S2. ThT fluorescence spectra of HSA pre titrated with PB (1:10) on ITC performed at 25 ${ }^{\circ} \mathrm{C}$ and $65^{\circ} \mathrm{C}$ 

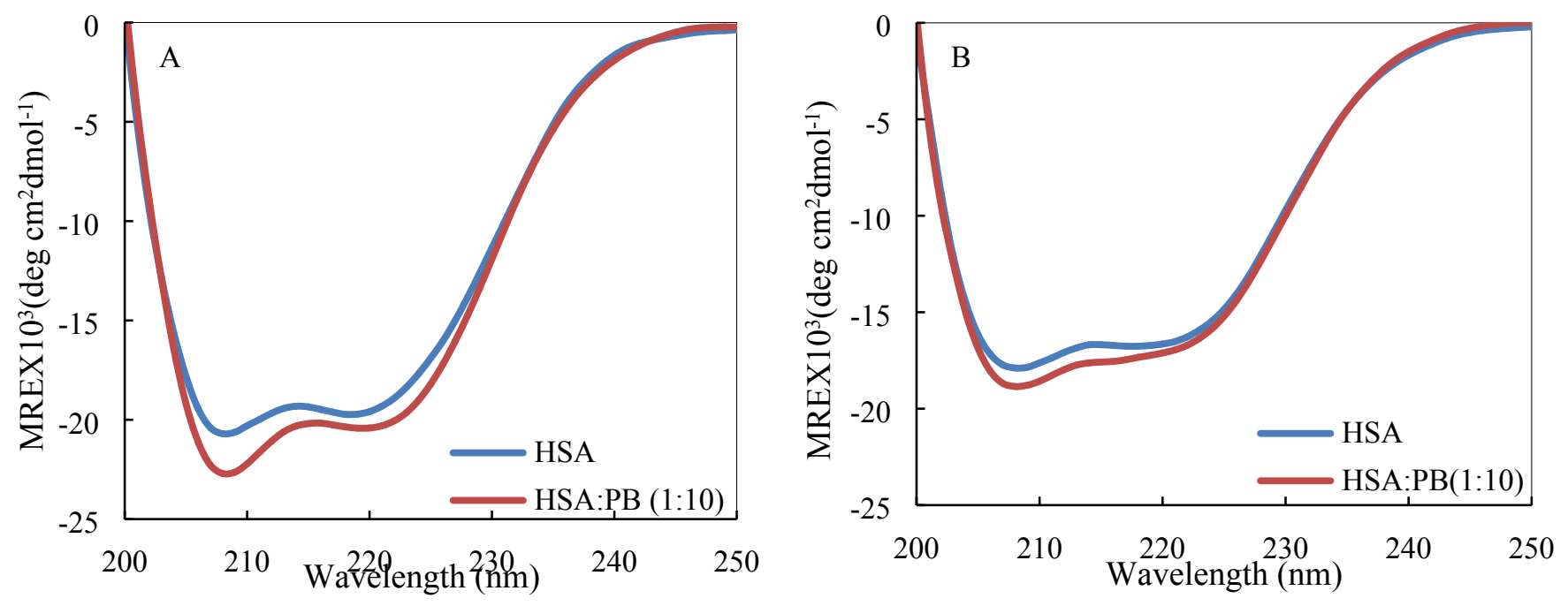

Figure S3. Far UV CD spectra of HSA alone and HSA pre titrated with PB on ITC at (A) $25^{\circ} \mathrm{C}$ and (B) $65^{\circ} \mathrm{C}$ 